\title{
IMPLICITOS E SILENCIAMENTOS COMO PISTAS IDEOLÓGICAS
}

\section{Maria do Socorro Aguiar de Oliveira Cavalcante (UFAL)}

\section{Introdução}

Interessa para este trabalho ver a partir de que posições sujeitos de diferentes grupos sociais apreendem a realidade e as determinações sociais que orientam os enunciantes na produção de sentidos.

Nessa perspectiva, consideramos imprescindivel a adoção de um conceito de linguagem que contemple seu papel constitutivo na incração social e a força ideológica de seus signos, cuja compreensão nào pode resultar de um ato passivo, descolado da realidade, uma vez que resulta do trabalho que os sujeitos realizam com e sobre a lingua, num processo contínuo de apropriação - objetivação. É através desse processo que o indivíduo constrói sua subjetividade e se constitui como sujeito. Isso, no entanto, não se dá de forma homogênea, mas $\mathrm{em}$ diferentes niveis de consciência, e varia de acordo com as relações que o individuo estabelece, tendo a linguagem como elemento que possibilita a percepção e efetivação dessas relações.

De igual relevância consideramos a necessidade de explicitar a noção de discurso a que nos filiamos, sem, no entanto, analisar as diferentes concepções atribuídas ao termo, quer nas diversas áreas da linguagem (Filologia, Lingüística do texto, Análise do Discurso), quer nas diversas tendências dentro de cada uma dessas áreas. Assumimos o entendimento de discurso enquanto práxis, resultado e possibilidade das relações sociais, ou como diz Maingueneau (1996:28), "atividade de sujeitos, inscritos em contextos determinados". Sendo produzido socialmente, em um determinado momento histórico. para responder às necessidades postas nas relações entre os homens para a produção e reprodução de sua existência, carrega o histórico e o ideológico dessas relaçōes. A partir desse entendimento, é de se esperar que sujeitos "inscritos" em diferentes contextos produzam discursos diferentes, ainda que em função de uma mesma temática. 
Sendo nosso intuito, neste trabalho, identificar e analisar as posições sujeito expressas nos recursos lingüísticos mobilizados na produção escrita, optamos por textos escritos, produzidos por alunos de segundo grau, de diferentes realidades sócio-econômicas.

Selecionamos então duas escolas da rede privada, freqüentadas por alunos das classes média-alta e elite, e duas escolas da rede pública, freqüentadas por alunos das classes média-baixa e popular, muitos deles já inseridos no mercado de trabalho. O próximo passo foi a delimitação do tema, que teria de ser significativo e concreto para os diferentes segmentos sociais. Optamos pelo tema violência, uma vez que, na nossa sociedade, ela faz parte do cotidiano de todos. Mantivemos contato com as professoras que se dispuseram a colaborar e solicitamos que, nas aulas de "redação", propusessem aos alunos escrever sobre o referido tema. Sugerimos que não houvesse discussão acerca do assunto, anteriormente, a fim de evitar influências (das opiniões do professor sobre os alunos). Sugerimos também que, no desenvolvimento do tema, os alunos abordassem suas causas, conseqüências e soluções para minimizar o problema. Recolhemos, ao todo, 94 redações, 54 das escolas particulares que designaremos de agora em diante com a sigla EPART, e 40 das escolas públicas, que designaremos com a sigla
EPUB.

\section{Uma leitura possível}

Várias são as alternativas para o conhecimento de um determinado objeto, contudo, o processo de conhecimento requer a definição de procedimentos teórico-metodológicos que permitam uma melhor aproximação do recorte da realidade tomado para análise. Tratando-se de um objeto que se concretiza mediado, especificamente, pela linguagem (oral ou escrita), recorreremos, na análise que exercitaremos nos textos acima referidos, às bases teóricometodológicas da Análise do Discurso (vertente francesa), por considerar que essa área nos fornece os recursos necessários para a realização desse estudo.

Tendo como objeto de estudo o discurso, entendido como práxis social, ou seja, como mediação das relações dos homens entre si, a AD coloca a exterioridade como marca fundamental e parte, segundo Orlandi (1986), de uma relação necessária entre o dizer e as 
condições de produção desse dizer. Pêcheux (1988:160) também afirma que "o sentido das palavras não pertence à própria palavra, /... / ao contrário. é determinado pelas posições ideológicas que estão em jogo no processo sócio-histórico, no qual as palavras, expressões e proposições são produzidas. " Dizendo de outro modo: os sentidos do discurso são determinados pela situação social mais imediata que, por sua vez, resulta do meio social mais amplo.

A partir dessas considerações, concluímos que as condições de produção do discurso compreendem, fundamentalmente, os sujeitos falantes em constante relação com a cultura', a sociedade e a economia de um determinado momento histórico. Nessa inter-relação os sujeitos assumem posições em relação a determinadas formações ideológicas e discursivas.

Formações ideológicas são a expressão da conjuntura ideológica de uma formação social que põe em jogo práticas associadas às relações de classe. Perus (1984:35) define formação ideológica como "campo contraditório que se define pelas relações de dominação/subordinação existente entre as ideologias em luta que o constituem.[...] Toda ideologia só existe em sua relação dinâmica e contraditória com as demais." Se aceitamos como função da ideologia o papel de seleção, hierarquização dos elementos culturais, podemos concluir que as formações ideológicas constituem matrizes comuns a um conjunto de discursos que expressam posições assumidas pelos sujeitos em diferentes práticas sociais. Cada formação ideológica contém, necessariamente, como um de seus componentes, uma ou várias formações discursivas.

O termo formação discursiva foi introduzido por Foucault (1969), em Arqueologia do saber, para designar os conjuntos de enunciados relacionados a um mesmo sistema de regras, historicamente determinadas. É daí que Pêcheux (1975:11) extrai esse

Assumimos aqui o conceito de cultura de Perus (1984:31): "Conjunto mais ou menos heterogêneo de elementos (materiais e espirituais) que saio produto de praticas diferenciadas histórica e concretamente dadas que, ao mesmo tempo que dão conta do dominio alcançado pela sociedade em seu conjunto sobre a natureza sob determinadas formas de organização social, servem de marco objetivo de referencias para a percepção subjetiva que têm os homens de seu lugar e seu papel na sociedade em que vivem." (tradução nossa). 
termo, dele se apropria, submete a um trabalho específico certos elementos conceituais e o introduz, na Análise do Discurso, como "aquilo que pode e deve ser dito (articulado sob a forma de uma palestra, aula, sermão, exposição, programa) a partir de uma posição dada em uma conjuntura dada." Assim concebida, uma formação discursiva estabelece um domínio de saber, um lugar em que as formações ideológicas operam, regulando os sentidos e estabelecendo formulações aceitáveis (o que pode e deve ser dito) e outras não aceitáveis (o que não pode e não deve ser dito).

É tarefa da $\mathrm{AD}$ explicar os caminhos da significação e os mecanismos de estruturação e interpretação do texto, entendido como possibilidade de acesso ao discurso. Daí que, segundo Orlandi (1996:60), "a relação proposta na $A D$ é: a) remeter o texto ao discurso; b) esclarecer as relações deste com as Formações Discursivas, pensando as relações destas com a ideologia.

É a partir desse referencial teórico que procederemos à análise dos textos. Queremos deixar claro o nosso entendimento de que o mesmo fato pode ser visto de modos diferentes, por analistas diferentes. Segundo Zima (1983:90): "uma construção possivel da realidade não é mais do que uma construção possivel e outras construções da mesma realidade são concebiveis e elas existem." Parafraseando Zima, diremos que a leitura que faremos dos textos em questão, é apenas uma leitura possível; outras existem.

Iniciaremos, pois, nosso trabalho pelo rastreamento das pistas lingüísticas fornecidas pelos textos, adotando os seguintes procedimentos de análise: a) o que dizem os textos; b) o que implicitam; c) o que silenciam. Conforme diz Voese (1995:5), "a primeira tarefa de uma análise do discurso é, observando e trabalhando as pistas, situar o que é dito."

\section{1 - O que dizem os textos?}

O trabalho de situar o que é dito prevê uma intervenção no texto, em termos de realizar recortes (R). Estes são fragmentos que englobam uma, duas ou mais orações, podendo até alcançar a totalidade de um parágrafo, e traduzem pontos de vista do enunciante frente ao tema proposto. A execução dessa tarefa nos possibilitou a organização dos quadros que apresentaremos a seguir. 


\section{QUADRO 1 - CAUSAS}

\begin{tabular}{|l|l|}
\hline EPART & EPUB \\
\hline R.2 - Tudo é culpa do governo. & $\begin{array}{l}\text { R.14-Essas violências são geradas } \\
\text { por governos corruptos. }\end{array}$ \\
\hline $\begin{array}{l}\text { R.5 - O governo ajuda para isso } \\
\text { porque não tem um plano eficaz que } \\
\text { resolva o problema da violência. }\end{array}$ & $\begin{array}{l}\text { R.5 - Falta de empenho dos } \\
\text { governos e dos políticos para acabar } \\
\text { com a fome a miséria. Eles só } \\
\text { pensam em encher os bolsos de } \\
\text { dinheiro. Dinheiro que vem dos } \\
\text { pobres e assalariados. }\end{array}$ \\
\hline $\begin{array}{l}\text { R.6 - Os que estão no poder nada } \\
\text { fazem, cruzam os braços e ficam } \\
\text { assistindo à desgraça alheia. }\end{array}$ & $\begin{array}{l}\text { R.13-Os próprios governantes do } \\
\text { nosso país nos roubam, pagando esse } \\
\text { salário de fome. }\end{array}$ \\
\hline $\begin{array}{l}\text { R.4 - O descaso governamental } \\
\text { também causa violência. }\end{array}$ & $\begin{array}{l}\text { A violència do trânsito, das drogas, } \\
\text { do estupro é causada por um } \\
\text { governo que não oferece melhorias } \\
\text { de vida. }\end{array}$ \\
\hline
\end{tabular}

Nesses recortes, os enunciantes de ambos os grupos atribuem ao governo a culpa pela violência. No entanto, percebemos diferentes formas de dizer. Os alunos das escolas particulares, embora reconheçam a inoperância e incapacidade do governo, atenuam sua culpabilidade sugerindo a existência de outros fatores (embora não explicitem quais) responsáveis pela violência - "o governo ajuda", " o descaso governamental também causa violência". Ajudar significa colaborar, contribuir, logo, quem ajuda não pode ser responsabilizado sozinho. O operador também dá idéia de inclusão. Logo, o governo não é responsabilizado sozinho, ele se soma a outros fatores que também contribuem para a violência.

Nos enunciados extraídos de textos de alunos das escolas públicas, os governos e políticos são responsabilizados e severamente julgados: "são corruptos, roubam, não se empenhem em acabar com a fome a miséria. [...] Só pensam em encher os bolsos de dinheiro. Dinheiro que vem dos pobres e assalariados."

Vejamos o quadro seguinte, que contém propostas de ações. sugeridas pelos alunos, para, pelo menos reduzir o indice de violência. 


\section{QUADRO 2 - SOLUÇÕES}

\begin{tabular}{|l|l|}
\hline EPART & EPUB \\
\hline $\begin{array}{l}\text { R.13 - Deve ser iniciado um } \\
\text { trabalho do governo para gerar } \\
\text { emprego, melhorar as condições de } \\
\text { vida do povo. }\end{array}$ & $\begin{array}{l}\text { R.6 Se houvesse governos mais } \\
\text { humanos que oferecessem possibili- } \\
\text { dades reais de sobrevivência. }\end{array}$ \\
\hline $\begin{array}{l}\text { R.4 - Basta que o governo tenha } \\
\text { dignidade, faça a vida dos cidadãos } \\
\text { se tornar mais digna. }\end{array}$ & $\begin{array}{l}\text { R.12 - Talvez se tivesse mais casa } \\
\text { de apoio a sociedade ajudasse um } \\
\text { pouco, quem sabe não seria } \\
\text { diferente? }\end{array}$ \\
\hline $\begin{array}{l}\text { R.6- Os homens que governam nosso } \\
\text { paí devem preocupar-se com as } \\
\text { coisas básicas como educação, saúde, } \\
\text { trabalho e, principalmente, uma } \\
\text { melhor distribuição de renda. }\end{array}$ & $\begin{array}{l}\text { R.7 - O governo teria que criar } \\
\text { medidas mais rigorosas na justiça. } \\
\text { periferias, nos carentes e capitais } \\
\text { pobres. Porque é dessas regiões } \\
\text { pobres que se origina a violência. }\end{array}$ \\
\hline $\begin{array}{l}\text { R.15 - Empregos devem surgir, não } \\
\text { esmolas. }\end{array}$ & $\begin{array}{l}\text { Nossa única solução para acabar } \\
\text { com a violência é Deus. }\end{array}$ \\
\hline
\end{tabular}

Também nesses recortes, as pistas lingüísticas revelam indícios da heterogeneidade cultural dos grupos, de sua identificação com diferentes formações discursivas. Os alunos das escolas particulares acreditam na possibilidade de resolver o problema da violência mediante ações governamentais. Isso se expressa através de modalizações ${ }^{2}$ que remetem ao governo o dever de tomar providências no sentido de acabar a violência, tais como: "deve ser iniciado um trabalho do governo"; "basta que o governo tenha dignidade"; "os homens que governam nosso país devem preocupar-se"; "devem surgir".

Ao apontar o emprego como solução, os alunos das escolas particulares o fazem a partir de uma formação discursiva própria da sociedade capitalista, estruturada em torno da relação capital/trabalho. Nesse modelo de sociedade, a classe dominante tem, na base econômica, o meio mais eficaz de solucionar problemas.

2 Segundo Cervoni, (1989:53): "A noção de modalidade implica a idéia de que uma análise semântica permite distinguir, num enunciado, um dito e uma modalidade - um ponto de vista do sujeito falante." 
Os alunos das escolas públicas expressam uma postura de descrença e/ou incerteza quanto à possibilidade de mudança através de ações do governo. Esse ceticismo se expressa, quer através de formulações em que os enunciantes afirmam só acreditar em soluções mediante intervenção divina, quer através de modalizações que expressam hipóteses, condições, dúvida: "se", "talvez", verbos no futuro do pretérito, frases interrogativas.

Quando vislumbram possibilidades de soluções mediante intervenção divina, os enunciantes também o fazem a partir de uma formação discursiva característica das classes subalternas e exploradas - a busca de soluções para os problemas através do mítico, do transcendental.

\subsection{Implícitos e silenciamentos}

Numa sociedade em que se verificam permanentes conflitos entre classes e grupos, a luta pelo silenciamento/manutenção ou construção de sistemas de referência ideológicos torna-se importante porque decide a orientação de condutas e de possiveis representações de mundo. Nesse contexto, o discurso é de grande importância como mediação, dentro de uma formação social. Segundo Amaral (1996:11), "o discurso é um modo de se pôr formas de ideologia. [...] Essas formas ideológicas encontram no discurso sua forma de objetivação."

Para definir ideologia, recorremos, aqui, a Perus (1984), que a concebe como mecanismo que seleciona (excluindo e incluindo) elementos culturais, rumo à homogeneização de concepções de mundo. "Desse modo, ela assume, no interior do campo cultural, um papel estruturador que consiste fundamentalmente em um processo de seleção, hierarquização, orientação e desenvolvimento, em um sentido determinado, dos elementos existentes." (op. cit. 34). E, à proporção que se elege um produto cultural como único correto e aceito, rejeitam-se os produtos culturais de outros segmentos. Isso, no entanto, não se dá de forma explícita, mas velada, às vezes quase imperceptível, uma vez que os conflitos ideológicos quase nunca se mostram, mas se alojam nas entranhas do discurso, à sombra das palavras. Como penetrar nas frinchas do discurso e desvendar sua trama? 
Isso só será possível se observarmos atentamente os indícios das determinações ideológicas nele sinalizadas. Esses indícios nos são fornecidos não só pelos elementos lingüísticos; há outros mecanismos discursivos que também nos fornecem pistas dessas determinações e são detectadas através da leitura do não-dito, ou seja, do que o texto deixa implícito ou silencia. Segundo Orlandi (1993:76), "em todo texto pode-se perceber a presença de um outro excluido, mas que o constitui. Ai está a ideologia." - no implícito e no silenciado.

Essa será a nossa próxima tarefa - fazer a leitura dos implicitos e silenciamentos a que nos remetem os textos dos alunos. Antes, porém, entendemos ser necessário definir tais conceitos que se aproximam, mas possuem características diferentes. No que se refere ao conceito de implícito, recorremos a Ducrot (1972:75). Diz ele:

São modos de expressão implícita que permitem deixar entender sem incorrer na responsabilidade de ter dito. [...] Ora, se tem freqüentemente necessidade de dizer certas coisas e ao mesmo tempo de poder fazer como se não as tivéssemos dito, de modo tal que se possa recusar a sua responsabilidade. $O$ não dito remete ao dito, tem com ele uma relação de dependência para significar.

Ou seja, o sujeito enunciante pode não assumir a autoria do texto implícito. Embora remeta ao dito, mantendo com ele uma relação de dependência para significar, o implicito é de responsabilidade do interlocutor, pois é trabalho de interpretação. É um mecanismo discursivo que faz o outro (interlocutor) dizer, no lugar do enunciante.

O silêncio, por sua vez, não depende do dito para significar: "o sentido do silêncio não deriva do sentido das palavras". diz Orlandi (1995:68), que assim se expressa sobre a "politica do silêncio" (op. cit. 75-76):

Se define pelo fato de que ao dizer algo apagamos necessariamente outros sentidos possiveis, mas indesejáveis, em uma situação discursiva dada.[...] Se diz ' $x$ ' para não (deixar) dizer ' 'y', este sendo o sentido a se descartar do dito. $\dot{E}$ o não dito necessariamente excluido. Por ai se apagam os sentidos que se quer evitar, sentidos que poderiam instalar o trabalho significativo de uma 'outra' formação discursiva. 
Vejamos agora alguns recortes dos textos produzidos pelos alunos de escolas públicas (EPUB) e particulares (EPART), tentando detectar o que eles deixam implícito e o que silenciam.

\section{CAUSAS}

EPUB - R.01 - A miséria gera violência. Pessoas desprezadas, sem ter de onde tirar suas necessidades básicas, roubam e até mesmo matam.

EPUB - R.16 - A maioria da violência é praticada pela classe pobre porque $95 \%$ dessas pessoas são analfabetas, não têm estrutura e acham que a violência resolve alguma coisa.

EPUB - R.15 - A causa dessa violência é a falta de emprego. a desigualdade social.

EPART - R.24 - Um dos principais fatores que geram a violência é a condição econômica do país, em que a maioria passa fome e vive em condições de miséria.

EPART - R.12 - Enquanto existir miséria, fome, a violência estará presente, seja nas grandes cidade, seja no interior, seja em qualquer parte.

EPART - R.07 A injustiça social, juntamente com a falta de oportunidades que o sistema oferece, limita a muitos o caminho do roubo, da violência, da falta de amor.

Analisando os recortes extraídos de textos dos dois grupos, constatamos a presença de implícitos que possibilitam leituras semelhantes. Como podemos observar, os enunciantes situam os focos de violência nas classe pobres, entre os desempregados e iletrados. Fazendo isso, nos remetem a um outro texto implícito - não existe violência na classe rica, letrada, que tem emprego. Podemos fazer a mesma constatação nos enunciados que seguem.

\section{SOLUÇÕES}

EPUB - R.12 - O governo teria de criar medidas mais rigorosas na justiça [...] teria de agir principalmente nas periferias, nos carentes e capitais pobres. Porque é dessas regiões pobres que se origina a violência.

EPUB - R. 09 - A educação. Sem ela estamos perdidos. 
EPUB - R. 22 - Não há como deter a violência, mas podemos amenizar com educação.

EPART - R. 18 - Se houvesse uma maior atenção do governo aos necessitados, tenho certeza de que grande parte da violência diminuiria consideravelmente.

EPART - R. 19 - Um planejamento governamental que desse mais ênfase à situação dos desempregados, ajudando-os durante este período.

EPART - R. 20 - A melhor solução para esse problema seria maior qualidade nas escolas públicas e cursos profissionalizantes que pudessem encaminhar esses jovens para um emprego digno.

Também nesses recortes os enunciantes nos possibilitam a mesma leitura implícita, excluindo a possibilidade de existir violência nas classes ricas e letradas, pois todas as propostas de soluções apontam para ações que devem ser executadas com relação à classe pobre - "maior atenção do governo aos necessitados", "mais ênfase à situação dos desempregados".

Quanto aos recortes que apontam a educação como solução, também identificamos textos implícitos que se identificam - os dois grupos acreditam na educação como uma instância autônoma, capaz de, sozinha, interferir nos rumos da sociedade e resolver o problema da violência. Situando o foco de violência nas pessoas iletradas, que não têm acesso à escola, os enunciantes remetem a uma leitura implícita que elimina a possibilidade de existir violência entre pessoas letradas, que têm acesso à educação. Nesse ponto, embora se identifiquem no âmbito geral, os enunciantes distinguem-se nas especificações. Vejamos.

Pelo que podemos depreender da leitura do recorte 09 - EPUB A educação. Sem ela estamos perdidos -, os alunos apontam a educação como solução, sem fazer restrições a sua qualidade. $O$ simples acesso à educação, não importa a qualidade, já concede, aos que têm esse privilégio, um "status" que os diferencia dos que não o têm. Já no recorte 20 - EPART, o enunciante propõe: "maior qualidade nas escolas públicas e cursos profissionalizantes que pudessem encaminhar esses jovens a um emprego digno." 
A leitura do citado enunciado nos remete ao entendimento de que, mesmo os que freqüentam a escola pública, não estão excluídos da condição de violentos, daí a necessidade de melhorar a qualidade dessa escola e oferecer cursos "profissionalizantes que pudessem encaminhar esses jovens a um emprego digno." Temos pois, que a possibilidade de solução para o problema da violência implica duas ações - maior qualidade nas escolas públicas e cursos profissionalizantes. Essas ações seriam direcionadas para um público específico - jovens de baixo poder aquisitivo que não têm dinheiro para pagar uma escola particular - e teriam um objetivo- encaminhar esses jovens para "um emprego digno."

Continuando o trabalho de rastreamento dos textos dos alunos, trabalharemos, a seguir, os silenciamentos presentes, tanto nos enunciados que se referem às causas, como nos que se referem às soluções.

Nos recortes que abordam as causas, através das escolhas mobilizadas, os governantes são responsabilizados e julgados. No entanto, silencia-se quanto ao modelo de sociedade vigente capitalista, excludente, que põe em primeiro lugar o lucro, depois as pessoas. Questionam-se os governantes (o que pode e deve ser dito), mas não se questiona o modelo de sociedade que permite que esses governantes assumam o poder (o que não pode e não deve ser dito). Nem de longe os enunciantes referem-se a um outro modelo de sociedade, como se, para mudar a realidade atual, fosse bastante mudar os dirigentes, sem mudar o atual modelo de sociedade.

Quanto às propostas de solução, seriam, a nosso ver, possibilidades de intervenção na realidade. Contrariando nossa expectativa, isso não aconteceu. As possibilidades de solução apresentadas são atribuídas ao governo ou a Deus (para os que não acreditam mais em soluções humanas) e vistas como doação, um ato de benevolência divina ou da classe dirigente, para com o povo. Ao produzir esses textos, mesmo sem disso ter consciência, os enunciantes silenciam um outro - a possibilidade de o povo reivindicar mudanças através de movimentos organizados. Essas mudanças não seriam doações, fruto da benevolência dos que detêm o poder, mas conquistas, fruto da luta dos setores organizados da sociedade.

Esse discurso, no entanto, não interessa à classe dominante, que constrói procedimentos discursivos para desconstruí-lo, pois, desconstruindo-se um discurso contra-hegemônico, silencia-se um 
outro modelo de sociedade, e, controlando-se as possibilidades de produção de representações de mundo, é possivel controlar as possibilidades de alteração da situação social no que diz respeito às relações de poder. Sendo o discurso de grande importância como mediação dentro de uma formação social, os setores dominantes criam mecanismos de controle que estabelecem limites às possibilidades de surgimento de discursos que representem ameaça à ordem estabelecida. Isso se dá, segundo Voese (1996:68),

Através de uma série de instrumentos que: a) fixam controles para a produção dos discursos; b) elaboram procedimentos discursivos que visam desconstruir a formação discursiva contrária; c) constroem, através da reiteração de um enunciado, a cristalização de uma imagem positiva do discurso de uma prática, de tal forma que ela se torne quase inquestionável..

Tais mecanismos são operacionalizados através de instituições como, por exemplo, o Direito, a Igreja, os Meios de Comunicação, a Educação, que, através da hierarquização de falas sociais em termos de certo $\mathrm{x}$ errado, bom $\mathrm{x}$ mau, moderno $\mathrm{x}$ atrasado, constroem uma representação de sociedade que sustenta os privilégios do segmento social que é dominante.

\section{Algumas constatações}

Ao se depararem com a temática proposta, os enunciantes dos dois grupos recorreram a pontos de vista dos discursos correntes (na midia, na imprensa) sobre o tema, incorporando-os e reproduzindo-os.

Para o quadro teórico da Análise do Discurso, nenhum discurso é produzido a partir do nada, mas a partir de outros discursos com os quais o enunciante dialoga, discorda, polemiza. Bakhtin (1975:86) também oferece esclarecimentos a esse respeito, quando diz:

O objeto do discurso de um locutor, seja ele qual for, não é objeto de discurso pela primeira vez neste enunciado, e este locutor nāo è o primeiro a falar dele: o objeto já foi falado, controvertido, esclarecido e julgado de diversas maneiras. Assim, o discurso deste locutor não pode deixar de relacionarse dialogicamente com as opiniōes de interlocutores imediatos, com as visões de mundo, as tendências ou teorias já lançadas sobre este objeto de discurso. 
Observando os noticiários e reportagens que a imprensa e a midia apresentam, percebemos que a violência é mostrada, com mais freqüência, nas favelas, nos presídios, entre as "gangs". Ora, e a que classe social pertencem as pessoas que vivem nesses locais? À classe pobre, é claro.

A serviço da classe dominante, os meios de comunicação cumprem um papel importante na homogeneização de concepções de mundo. Falam da violência, da miséria, do desemprego, falam até dos governos corruptos, mas silenciam sobre a origem desses fenômenos, ocultam a lógica de seu aparecimento. Essa é uma forma que a ideologia encontra para desconstruir o diferente, homogeneizando-o. Desconstruindo-se o diferente, mistifica-se o discurso dominante, mascarando a realidade, controlando/apagando as manifestações de conflitos que se originam na héterogeneidade social.

O processo de mistificação de determinada prática social visa a conferir um poder ao discurso e ocultar o seu comprometimento com uma situação. Isso se dá através do processo de construção de determinados conceitos, impedindo a desconstrução critica, fazendo passar como verdadeiro e definitivo aquilo que não é. A mistificação é uma das principais estratégias da ideologia dominante. A esse respeito, assim se posiciona Mészáros (1993:10):

Deve-se enfatizar que o poder da ideologia é indubitavelmente enorme, não só pelo esmagador poder material e por um equivalente arsenal político-cultural à disposição das classes dominantes, mas sim, porque esse poder ideológico só pode prevalecer graças à posição da mistificação, através da qual os receptores potenciais podem ser induzidos a endossar consensualmente, valores e diretrizes práticas que são, na realidade, totalmente adversos a seus interesses vitais. (Grifo nosso).

A partir da análise realizada nos textos dos alunos, podemos afirmar com Mészáros (op.cit.) que os enunciantes - "receptores potenciais" -, não dispondo de um referencial que lhes possibilite fazer uma leitura crítica dos discursos correntes, os endossam e os incorporam, sem nem mesmo perceber que estão indo de encontro aos seus próprios interesses. Arriscamos ainda afirmar que, provavelmente, eles não se dêem conta das leituras que seus textos possibilitam. Acreditamos ainda na possibilidade de, interrogados acerca dos implícitos que seus textos deixam transparecer, mostrarem- 
se surpresos ou até argumentarem: "Não foi isso que elu quis dizer". A nosso ver, isso acontece porque o trabalho de produção de textos na escola. da forma como vem sendo feito (cf. Cavalcante. 1997)", não possibilita ao aluno apreender a intencionalidade dos diversos discursos, a multiplicidade de interpretações e as manobras discursivas neles contidas, com o intuito de passar una visão de mundo como a única correta. Agindo assim, a instituiçào escolar também está contribuindo para a construção de uma representação de sociedade que, como já dissemos, sustenta os privilégios do segmento social dominante.

Não se pode, pois. desconhecer as relações que se estabelecem entre lingua e poder. Não se pode mais considerar a produção lingüistica apenas como a capacidade de uma lingua, mas também como o domínio das regras sociais que controlam tanto a produção quanto a circulação dos discursos, pois, numa sociedade de classes, a possibilidade de constituição e imposição de representações de mundo se dá no e pelo discurso.

\section{REFERÊNCIAS BIBILOGRÁFICAS}

AMARAL, M. Virginia Borges. Análise do discurso da ABISSS: desvendando os limites da profissão. Dissertação de Mestrado em Letras. Maceió, UFAL, 1994. BAKHTIN, Mikail. Marxismo e filosofia da linguagem. São Paulo:
Ilucitec.1982.

(AVAlCANTE, M. do Socorro Aguiar de Oliveira. Produção de texto na escola: Homogeneização do não homogêneo. Dissertação de Mestrado em Letras. Maceió, UFAL, 1997.

CAVALCANTE, M. do Socorro Aguiar de Oliveira. A língua sob o olhar da Análise do Discurso. In: MOURA, Maria Denilda (org.). Os muiltiplos usos da lingua. Maceió: Edufal,. 1999.

Dissertação de mestrado: PRODLÇÃO DE TEXTO NA I:SCOIA: HOMOGENEIZAÇÃO DO NÃO HOMOGÊNEO. 
CERVONI, Jean. A enunciação. São Paulo: Ática, 1989.

DUCROT, Osvald. Dire et ne pas dire. Paris: Herman, 1972.

Maingueneau, Dominique. Novas tendências em Análise do Discur:so. Campinas.1989.

MAINGUENEAU, Dominique. Les termes clés de l'analise du discours. Paris: SEUIL, 1996.

MÉSZÁROS, Izvan. El poder de la ideologia. Dialética, Puebla, México, ano X, n. 17, 1985.

ORLANDI, Eni Puccinelli. As formas do silêncio no movimento dos sentidos. Campinas: UNIGAMP, 1993.

PÎ:C HEUX. Michel. Semântica e discurso: uma crítica à afirmação do ihvio. Campinas: UNICAMP, 1988.

PERUS, Françoise. Cultura, ideologia, formaciones ideológicas y prácticas discursivas. Cuadernos de teoria y análisis. México, n. 5, p.29-39. 1984.

VOESE, Ingo. O movimento dos sem-terra na imprensa: um exercício de análise do discurso. Ijuí: UNIJUÍ, 1998.

7.IMA, Peter. Los mecanismos discursivos de la ideologia. Semiosis, n. 11, p.73-96, 1983. 